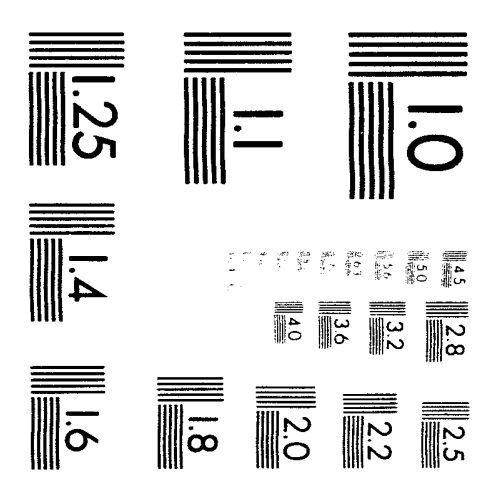



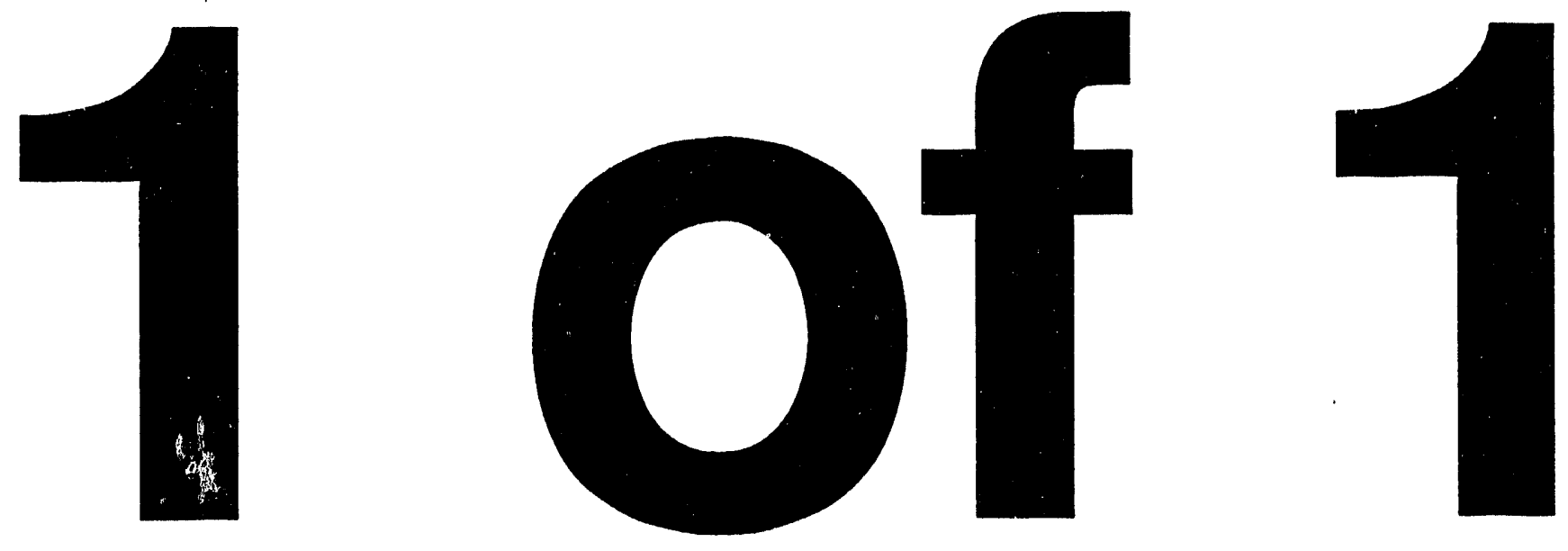
Calculations of Material Removal, Removal Rate, and Preston Coefficient in Continuous Lapping/Polishing Machines

P. Paul Hed

Materials Fabrication Division

October 18,1993

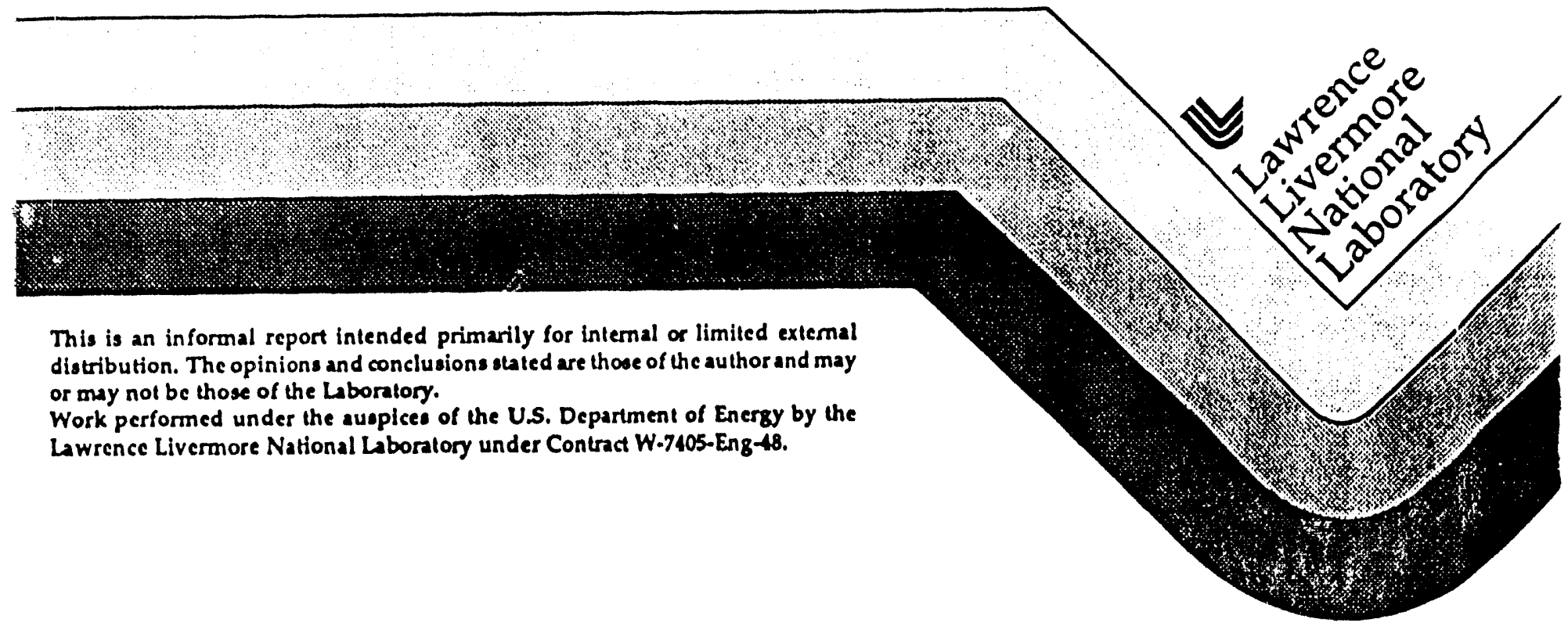

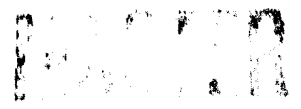




\section{DISCLAIMER}

This document was prepared as an account of work sponsored by an ageacy of the Unlled States Governmenc. Neither the Uniled States Government nor the Univerdity of Calliforala sor any of their employ ees, makes ans wartanty, express or implled, or assumes any legal liablilty or responsiblity for the accuracy, completenex, or usefulness of any information, apparatus, product, or process disclosed, or represents that its use would wot infringe privalely owned rights. Reference herein 1020 y specific commerdal products, process, or service by trade na me, tradem ark, manufacture, or ocherwise, does nol necessarilly consellute or imply its endorsement, recommendation, or favoring by the Unilled States Government or the Universtly of Callfornta. The views and opinions of authors expressed herein do not necessarlly stale or reflect those of the United States Government or the University of Californla, and shall not be used for ad vertlsing or product endorsem ent purposes.

This report has been reproduced directly from the best available cops.

Available to DOE and DOE contractors from the

Orice of Scientific and Technical Information

P.O. Box 62, Oak Ridge, TN 37831

Prices a vailable from (615) 576-8401, FTS 626.8401

Available to the public from the

National Tectnical Information Service

US. Department of Commerce

5285 Port Royal Rd,

Springtield, VA 22161 


\title{
Calculations of Material Removal, Removal Rate, and Preston Coefficient in Continuous Lapping/Polishing Machines
}

\author{
P. Paul Hed \\ Materials Fabrication Division \\ Lawrence Livermore National Laboratory \\ Livermore, CA 94551
}

\section{Introduction}

Lapping and polishing machines usually do not have deterministic model to predetermine removal rate and total material to be removed. The removal process is mainly affected by the relative motion between the lap and the substrates, by the load applied, and by the mechano-chemical characteristics of the substrate material, as well as the abrasive and lap materials. Therefore, frequent measurements of the removal is necessary.

This paper, which was written for optical technicians, includes formulas to calculate material removal from mass loss and removal rate from mass loss during operation. Establishing the removal rate helps by reducing the frequency of intermediate thickness measurements. The paper also includes the calculation of Preston coefficient, which is a measure of the lapping process efficiency.

\section{Material Removal (General case)}

The removed mass, or weight $(\Delta M)$, of the material is equal to its removed volume $(\Delta V)$ times its specific gravity or density $(\rho)$. Since, for smooth flat surfaces, $\Delta V=$ substrate area $(A) \times$ removed height $(\Delta H)$, we can say that $\Delta M=$ A $x \Delta H \times \rho$. Therefore, the material removed $\Delta H$, in $\mu \mathrm{m}$, is given by:

$$
\Delta \mathrm{H}=\frac{\Delta \mathrm{M} \times 10^{4^{*}}}{\mathrm{~A} \times p}
$$

where

$$
\begin{aligned}
& \Delta M-\text { mass (weight) loss in } \mathrm{g} \\
& \mathrm{A} \text { - area of substrate in } \mathrm{cm}^{2} \\
& \rho \text { - density (specific gravity) of substrate in } \mathrm{g} / \mathrm{cm}^{3}
\end{aligned}
$$

Example:

$$
\begin{aligned}
\begin{aligned}
\Delta M & =0.2731 \mathrm{~g} \\
A & =42.5 \mathrm{~cm} 2 \\
\rho & =2.53 \mathrm{~g} / \mathrm{cm}^{3}
\end{aligned} \\
\quad \Delta H=\frac{0.2731 \times 10^{4}}{42.5 \times 2.53}=25.4 \mu \mathrm{m}\left(.001^{\prime \prime}\right)
\end{aligned}
$$

* Note: The $10^{4}$ multiplier has been introduced to convert $\Delta \mathrm{H}$ to $\mu \mathrm{m}$ from $\mathrm{cm}$ $\left(1 \mathrm{~cm}=10^{4} \mu \mathrm{m}\right)$. 
Approximately $200-250 \mu \mathrm{m}\left(.008 "-.010^{\prime \prime}\right)$ of glass material should be removed during loose abrasive lapping. The exact amount depends on the depths of subsurface damage (SSD) left after the previous operations. The SSD is a function of the grinding parameters and the glass type, and will not be discussed here. During polishing, which follows lapping with $9 \mu \mathrm{m}$ alumina slurry, about $12 \mu \mathrm{m}$ of material should be removed from fused silica and $14 \mu \mathrm{m}$ from BK-7 glass.

Preston (1927) suggested that the amount of the material removed during lapping ( $\Delta \mathrm{V}$ or $\Delta \mathrm{M}$ ) is directly proportional to both local pressure and relative motion between the part and the lap. When we look at this closely, we realize that the removal is independent of the substrate roughness. The reason is that the rougher the surface, the smaller the contact area is; therefore, a larger local pressure will result. One should conclude then that in fact the removal is proportional to the applied load.

One might argue that $\Delta \mathrm{M}$ varies somewhat with the surface roughness and it causes a certain amount of inaccuracy when one calculates $\Delta H$ for the transit phase between one surface roughness to another, e.g., between surface finish obtained with $9 \mu \mathrm{m}$ lapping and a polished surface. In reality, this is not a big issue, since the thickness of this layer is very small, especially in comparison to the amount of material to be removed to eliminate the subsurface damage. For example, after lapping of fused silica with $9 \mu \mathrm{m}$ alumina slurry, the surface roughness is approximately $1.9 \mu \mathrm{m}$ $\mathrm{P}-\mathrm{V} / 0.2 \mu \mathrm{m} \mathrm{Ra}$. This means that we can assume the surface as being made of a large amount of conic pyramids, $0.2 \mu \mathrm{m}$ tall, touching each other in their base. Therefore, the volume of this rough layer is equal to the area of the part times $1 / 3$ of the pyramids height, i.e., $0.07 \mu \mathrm{m}$. This is the equivalent height that should be removed. It is, obviously, negligible in comparison to the $12 \mu \mathrm{m}$ which has to be polished.

The sensitivity of measuring the removal is higher by calculating $\Delta H$ from $\Delta M$ than by using mechanical means, such as a micrometer. The following will illustrate this point. Removing $1 \mu \mathrm{m}$ from a surface of a $48.29 \mathrm{~mm}$ fused silica disc reduces its mass by 0.0040 grams. Since we can measure the mass of parts weighing under 200 grams to $\pm 0.0001 \mathrm{~g}$ accuracy, we can establish the removal to $\pm 1 / 40 \mu \mathrm{m}$, or $\pm 0.025 \mu \mathrm{m}$ $(\sim \pm 1.6 \mu$-in. $)$.

\section{Material Removal (Round discs)}

Many of the parts in the optics shop are round in shape, some are even discs of standard size. Therefore, most of the formulas throughout this paper will be given for discs.

The material removed $\Delta H$, in $\mu \mathrm{m}$, is given by:

$$
\Delta H=\frac{\Delta M \times 4 \times 10^{4}}{\pi \times D^{2} \times p}
$$

where

$$
\begin{aligned}
& \Delta M \text { - mass (weight) loss in } \mathrm{g} \\
& D \text { - effective diameter of substrate (between chamfers) in } \mathrm{cm} \\
& \rho \text { - density (specific gravity) of substrate in } \mathrm{g} / \mathrm{cm}^{3}
\end{aligned}
$$


Example:

$$
\begin{aligned}
& \Delta \mathrm{M}=0.0213 \mathrm{~g} \\
& \mathrm{D}=4.623 \mathrm{~cm} \\
& \rho=2.202 \mathrm{~g} / \mathrm{cm}^{3} \\
& \Delta H=\frac{0.0213 \times 4 \times 10^{4}}{\pi \times 4.623^{2} \times 2.202}=5.76 \mu \mathrm{m}\left(\sim .0002^{\prime \prime}\right)
\end{aligned}
$$

\section{Removal Rate}

Removal rate (RR) is the average material removed in a unit of time (hours, minutes, etc.). To obtain the removal rate, we divide the amount of material removed by the total amount of time. Thus,

$$
R R=\frac{\Delta H}{\Delta T}
$$

where

$$
\begin{aligned}
& \Delta H \text { - material removed in } \mu \mathrm{m} \\
& \Delta \mathrm{T} \text { - total run time in } \mathrm{h} \text { (hours) }
\end{aligned}
$$

Example:

$$
\begin{aligned}
\Delta \mathrm{H} & =5.76 \mu \mathrm{m} \\
\Delta \mathrm{T} & =(375 \mathrm{~min} .)=6.25 \mathrm{~h}
\end{aligned}
$$

$$
\mathrm{RR}=\frac{5.76}{6.25}=0.92 \mu \mathrm{m} / \mathrm{h}
$$

The removal rate can be calculated with one formula by combining (2) with (3). Thus,

$$
R R=\frac{\Delta \mathrm{M} \times 4 \times 10^{4}}{\Delta \mathrm{T} \times \pi \times \mathrm{D}^{2} \times p}
$$

Example:

$$
\begin{aligned}
& \Delta M=0.0213 \mathrm{~g} \\
& \Delta T=6.25 \mathrm{~h} \\
& D=4.623 \mathrm{~cm} \\
& \rho=2.202 \mathrm{~g} / \mathrm{cm}^{3}
\end{aligned}
$$

$$
\mathrm{RR}=\frac{0.0213 \times 4 \times 10^{4}}{6.25 \times \pi \times 4.623^{2} \times 2.202}=0.92 \mu \mathrm{m} / \mathrm{h}
$$

Theoretically, it is possible to predict the length of time required to remove a certain amount of material based on measuring the removal after a fraction of the time, say, 15 minutes. In reality this is not the case, since the substrate may have not reached to matching curvature of the lap. Therefore, more than one measurment will be required. It may sometimes be convenient to measure the removal rate on a monitor 
part, made of the same material and running simultaneously. Here, it is important to verify that monitor and workpiece rotate at the same speed and that both run under the same pressure. If the pressure (i.e., load over area) is different, a correction in the calculation should be made, considering Preston hypothesis which proposes that within certain limits the removal rate is directly proportional to the pressure.

Under the pressure of $25 \mathrm{~g} / \mathrm{cm}^{2}$, the $36^{\prime \prime}$ brass lapping machine, rotating at $17-1 / 2$ $\mathrm{rpm}$ (substrate speed $1,885 \mathrm{~cm} / \mathrm{min}$ ), and using $9 \mu \mathrm{m}$ alumina, removes about $46 \mu \mathrm{m} / \mathrm{h}$ of BK.7 glass and $31 \mu \mathrm{m} / \mathrm{h}$ of fused silica ( $33 \%$ less). Under the same pressure, the $48^{n} \mathrm{Zygo}$ C.P. machine, rotating at $3 \mathrm{rpm}$ (substrate speed $766 \mathrm{~cm} / \mathrm{min}$ ) removes about $1.7 \mu \mathrm{m} / \mathrm{h}$ of BK-7 glass and $0.7 \mu \mathrm{m} / \mathrm{h}$ of fused slicia ( $58 \%$ less).

\section{Process Efficiency us. Fabrication Efficiency}

During fabrication, the removal rate can be affected by changing the pressure between the substrate and the lap, or by changing the relative motion between them. For example, increasing the pressure by a factor of 2 will increase the material removal by 2 ; increasing the speed by 3 will increase the removal by 3 ; increasing both pressure and speed will increase the removal by $2 \times 3=6$ times. This is basically Preston hypothesis which is accurate to a first approximation. As much as this is important to fabrication efficiency, it has nothing to do with process efficiency. Process efficiency is defined as the ratio of output derived in a machine to the energy applied to it. This way, if the increased input (say, speed) results in the same increase in output (material removed), the process efficiency hasn't changed (although the fabrication efficiency did). But if we increase the output without changing the energy input, we have changed the process efficiency.

Process efficiency can be changed, for example, by changing the lap material. Replacing brass with cast iron laps increases the material removal by approximately $20 \%$. Here we can say that the process efficiency has increased by $20 \%$. Putting grooves in laps increases the efficiency too. Tesar and Fuchs ${ }^{1}$ reported an increase in polishing efficiency of fused silica by treating the polishing slurry chemically.

In order to find the value of the process efficiency factor, we have to give each pressure and speed a value of 1 . We do it by dividing the mass removed $(\Delta M)$ by the actual values of the pressure and speed. This is called "normalizing". It is as if we say that we want to know what the removal would be if the pressure in the run was only $1 \mathrm{~g} / \mathrm{cm}^{2}$ and the speed only $1 \mathrm{~cm} / \mathrm{min}$. Because of scientific-mathematical reasons, our process efficiency factor is given in $\mathrm{cm}^{2} /$ dyne $(1$ dyne $=1 / 981 \mathrm{~g}$. $)$. It could have been given in $\mathrm{cm}^{2} / \mathrm{g}$ instead but there are already a lot of published data where $\mathrm{cm}^{2} /$ dyne has been used that I can not justify changing it now. The removal process efficiency factor is sometimes called Preston coefficient.

The Preston coefficient allows comparisons with results from other runs having slightly different mechanical parameter. It becomes, then, more useful than just recording removal rates. 2 Thus, one can compare the efficiencies of process which differ in lap size, lap speed, load, and length of runs. The higher the value of the Preston coefficient the higher the process efficiency is. Later, I will show how to convert the Preston coefficient to removal rates for various machining parameters.

\section{Calculating Preston Ceefficient (Accurate way)}

In order to take the data for calculating the Preston coefficient accurately, the machine has to be equipped with a counter to count the number of revolutions the lap makes during the run. This gives a correct value of the substrate path on the lap. 
The Preston coefficient $C$, in $\mathrm{cm}^{2} /$ dyne, is given by:

$$
C=\frac{\Delta M}{N_{R E V} \times 2 R \pi \times L \times 981 \times p}
$$

where

$$
\begin{aligned}
& \triangle M \text { - mass (weight) loss in } \mathrm{g} \\
& \text { NREV - number of lap revolutions during a given run } \\
& \mathrm{R} \text { - distance from center of Lap to center of septum in } \mathrm{cm} \\
& \mathrm{L} \text { - total load on substrate (i.e., total weight of substrate and of } \\
& \text { "weights" above it) in } \mathrm{g} \\
& \rho \text { - density (specific gravity) of substrate in } \mathrm{g} / \mathrm{cm}^{3}
\end{aligned}
$$

Note that Preston coefficient contains load (L) but not substrate area or pressure.

Example:

$$
\begin{aligned}
& \Delta M=0.0213 \mathrm{~g} \\
& \text { NREV }=1,125 \\
& R=40.64 \mathrm{~cm}\left(Z_{y g o} \text { C.P. }\right) \\
& L=534.4 \mathrm{~g} \\
& \rho=2.202 \mathrm{~g} / \mathrm{cm}^{3} \\
& C=\frac{0.0213}{1,125 \times 2 \times 40.64 \times \pi \times 534.4 \times 981 \times 2.202}=6.423 \times 10^{-14} \mathrm{~cm}^{2} / \text { dyne }
\end{aligned}
$$

\section{Calculating Preston Coefficient (Approximate way)}

When a machine is not equipped with a lap revolution counter, the lap RPM, as well as the length of run time, should be recorded. This is a less accurate procedure than the previous one, since the RPM fluctuate during the day and the exact path length of the substrate isn't known. The approximate Preston coefficient $\mathrm{C}_{\text {approx., in }} \mathrm{cm}^{2 / d y n e}$, is then given by:

$$
C_{\text {approx. }}=\frac{\Delta M}{N_{R P M} \times \Delta t \times 2 R \pi \times L \times 981 \times p}
$$

where

$\Delta \mathrm{M}$ - mass (weight) loss in $\mathrm{g}$

NRPM - number of lap revolutions per minute

$\Delta t$ - run time in minutes

$\mathrm{R}$ - distance from center of lap to center of septum in $\mathrm{cm}$

$\mathrm{L}$ - total load on substrate (i.e., total weight of substrate and of "weights" above it) in $\mathrm{g}$

$P$ - density (specific gravity) of substrate in $\mathrm{g} / \mathrm{cm}^{3}$ 
Example:

$$
\begin{aligned}
& \Delta \mathrm{M}-0.0213 \mathrm{~g} \\
& \text { NRPM }-3(\text { Zygo C.P. }) \\
& \Delta \mathrm{t}-375 \mathrm{~min} . \\
& \mathrm{R}-40.64 \mathrm{~cm} \\
& \mathrm{~L}-534.4 \mathrm{~g} \\
& \rho-2.202 \mathrm{~g} / \mathrm{cm}^{3} \\
& \mathrm{C}_{\text {approx. }}=\frac{0.0213}{3 \times 375 \times 2 \times 40.64 \times \pi \times 534.4 \times 981 \times 2.202}=6.423 \times 10^{-14} \mathrm{~cm}^{2} / \text { dyne }
\end{aligned}
$$

Note: Examples of removal forms are enclosed.

\section{Calculating Removal Rate with Preston Coefficient}

We can use Preston coefficient to calculate the removal rate on different substrate diameters and various machining parameters, such as lap size, applied load and relative speed.

$$
R R=C \frac{8 \times 10^{4} \times N_{\text {REV }} \times R \times L \times 981}{D^{2} \times \Delta T}
$$

where

RR - removal rate in $\mu \mathrm{m} / \mathrm{h}$

C - Preston coefficient in $\mathrm{cm}^{2} /$ dyne

NREV - number of lap revolutions during a given run

$\mathrm{R}$ - distance from center of lap to center of septum in $\mathrm{cm}$

$\mathrm{L}$ - total load on substrate (i.e., total weight of substrate and of weights above it) in $g$.

D - effective diameter of substrate (between chamfers) in $\mathrm{cm}$ $\Delta T$ - total run time in $h$ (hours)

Example:

$$
\begin{aligned}
& \mathrm{C}=6.423 \times 10^{-14} \mathrm{~cm}^{2} / \text { dyne } \\
& \text { NREV }=1,125 \\
& R=40.64 \mathrm{~cm} \\
& L=534.4 \mathrm{~g} \\
& D=4.623 \mathrm{~cm} \\
& \Delta T=6.25 \mathrm{~h} \\
& R R=\frac{6.423 \times 10^{-14} \times 8 \times 10^{4} \times 1,125 \times 40.64 \times 534.4 \times 981}{4.623^{2} \times 6.25}=0.92 \mu \mathrm{m} / \mathrm{h}
\end{aligned}
$$

The following formula makes it even simpler and faster to calculate the approximate removal rate.

$$
\mathrm{RR}_{\text {approx. }}=\mathrm{C} \frac{48 \times 10^{5} \times \mathrm{N}_{\mathrm{RPM}} \times \mathrm{R} \times \mathrm{L} \times 981}{\mathrm{D}^{2}}
$$


Date

Machine:

Lap speed:

RPM

$R$ - Lap average Radius

$\mathrm{cm}$

Lap Material:

Compound:

Concentration

\begin{tabular}{|c|c|c|c|}
\hline & Part No. & & \\
\hline & Part Material & & \\
\hline$p$ & Material density $\left(\mathrm{g} . / \mathrm{cm}^{3}\right)$ & & \\
\hline $\mathrm{M}_{1}$ & Mass of "weight" (g.) & & \\
\hline $\mathrm{M}_{2}$ & Mass of part (g.) & & \\
\hline $\mathrm{L}$ & Total load, $M_{1}+M_{2}$ (g.) & & \\
\hline D & Part effective dia. $(\mathrm{cm})$ & & \\
\hline $\mathrm{M}_{0}$ & Mass before run (g.) & & \\
\hline To & Time run started & & \\
\hline $\mathrm{T}_{\mathrm{t}}$ & Time run ended & & \\
\hline$\Delta \mathrm{T}$ & Total run time, $T_{t}-T_{o}(h)$. & & \\
\hline NREV & Total number of lap revolutions & & \\
\hline $\mathrm{M}_{\mathrm{t}}$ & Mass after run (g.) & & \\
\hline$\Delta \mathrm{M}$ & Mass lost, $M_{0} \cdot M_{t}(\mathrm{~g})$. & & \\
\hline$\Delta H$ & Material removed $(\mu \mathrm{m})$ & & \\
\hline RR & Removal rate $(\mu \mathrm{m} / \mathrm{h})$. & & \\
\hline $\mathrm{C}$ & Preston coefficient ( $\mathrm{cm}^{2} /$ dyne) & & \\
\hline
\end{tabular}

Remarks:

$$
\mathrm{RR}=\frac{\Delta \mathrm{M} \times 4 \times 10^{4}}{\Delta \mathrm{T} \times \pi \times \mathrm{D}^{2} \times p}
$$

$C=\frac{\Delta M}{N_{R E V} \times 2 R \pi \times L \times 981 \times \rho}$ 
where:

$R R_{\text {approx. - approximate removal rate in } \mu \mathrm{m} / \mathrm{h}}$

$\mathrm{C}$ - Preston coefficient in $\mathrm{cm}^{2} /$ dyne

NRPM - number of lap revolutions per minute

$R$ - distance from center of lap to center of septum in $\mathrm{cm}$

$\mathrm{L}$ - total load on substrate (i.e., total weight of substrate and of "weights" above it) in $g$

D - effective diameter of substrate (between chamfers) in $\mathrm{cm}$

Example:

$$
\begin{aligned}
& \mathrm{C}=6.423 \times 10^{-14} \mathrm{~cm}^{2} / \text { dyne } \\
& \text { NRPM }=3 \\
& \mathrm{R}=40.64 \mathrm{~cm} \\
& \mathrm{~L}=534.4 \mathrm{~g} \\
& \mathrm{D}=4.623 \mathrm{~cm} \\
& \mathrm{RR}_{\text {approx. }}=\frac{6.423 \times 10^{-14} \times 48 \times 10^{5} \times 3 \times 40.64 \times 534.4 \times 981}{4.623^{2}}=0.92 \mu \mathrm{m} / \mathrm{h}
\end{aligned}
$$

1. A. A. Tesar and B. A. Fuchs, "Removal rates of fused silica with cerium oxide/pitch polishing" in Advanced Optical Manufacturing and Testing II, V. J. Doherty, ed., Proc. SPIE - Intl. Soc. Opt. Eng., 1531, 80-90 (1991).

2. N. J. Brown, "Optica! Fabrication," UCRL-MISC-4476, Rev. 1, LLNL, 6, (1989). 
Date

Machine:

NRPM: RPM

$\mathrm{K}$ - Lap average Radius $\mathrm{cm}$

Lap Material:

Compound:

Concentration

\begin{tabular}{|l|l|l|l|}
\hline & Part No. & & \\
\hline & Part Material & & \\
\hline $\mathrm{M}_{1}$ & Material density $\left(\mathrm{g} . \mathrm{cm}^{3}\right)$ & & \\
\hline $\mathrm{M}_{2}$ & Mass of "weight" $(\mathrm{g})$. & & \\
\hline $\mathrm{L}$ & Mass of part $(\mathrm{g})$. & & \\
\hline $\mathrm{D}$ & Total load, $\mathrm{M}_{1}+\mathrm{M}_{2}(\mathrm{~g})$. & & \\
\hline $\mathrm{M}_{\mathrm{O}}$ & Mart effective dia. $(\mathrm{cm})$ & & \\
\hline $\mathrm{T}_{\mathrm{O}}$ & Time run started & & \\
\hline $\mathrm{T}_{\mathrm{t}}$ & Time run ended & & \\
\hline$\Delta \mathrm{T}$ & Total run time, $\mathrm{T}_{\mathrm{t}} \cdot \mathrm{T}_{\mathrm{O}}(\mathrm{h})$. & & \\
\hline $\mathrm{M}_{\mathrm{t}}$ & Mass after run $(\mathrm{g})$. & & \\
\hline$\Delta \mathrm{M}$ & Mass lost, $\mathrm{M}_{\mathrm{O}} \cdot \mathrm{M}_{\mathrm{t}}(\mathrm{g})$. & & \\
\hline$\Delta \mathrm{H}$ & Material removed $(\mu \mathrm{m})$ & & \\
\hline $\mathrm{RR}$ & Removal rate $(\mu \mathrm{m} / \mathrm{h})$. & & \\
\hline $\mathrm{C}_{\mathrm{aprx}}$ & Preston coefficient $(\mathrm{cm} / \mathrm{dyne})$ & & \\
\hline
\end{tabular}

Remarks:

$$
R R=\frac{\Delta M \times 4 \times 10^{4}}{\Delta \mathrm{T} \times \pi \times D^{2} \times \rho}
$$$$
\mathrm{C}_{\text {approx. }}=\frac{\Delta \mathrm{M}}{\mathrm{N}_{\mathrm{RPM}} \times \Delta \mathrm{T} \times 2 \mathrm{R} \pi \times \mathrm{L} \times 981 \times \rho}
$$ 

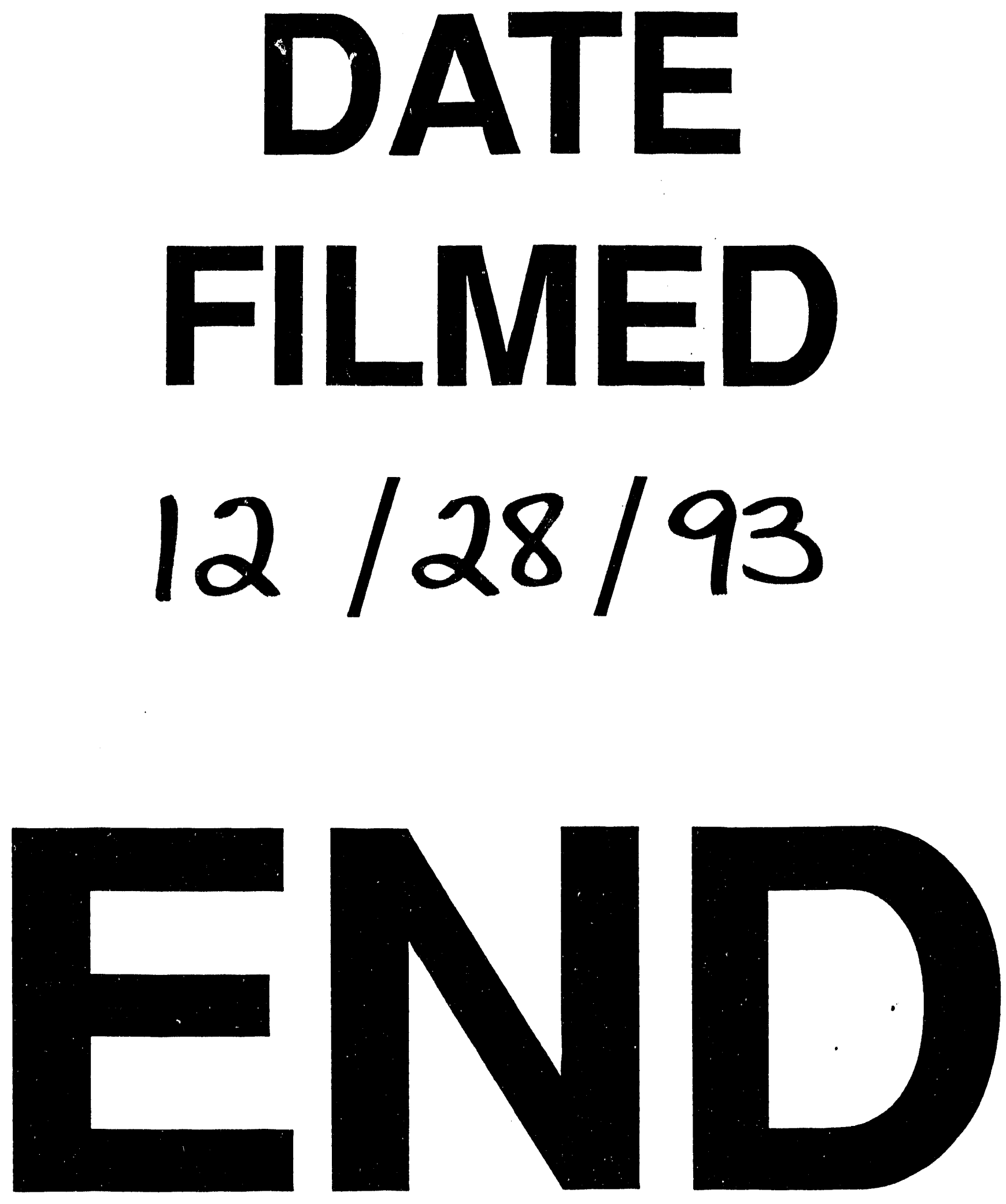
